\title{
Antioxidant activity and antiapoptotic effect of Asparagus racemosus root extracts in human lung epithelial H460 cells
}

\author{
LALANA KONGKANERAMIT ${ }^{1}$, WASU WITOONSARIDSILP ${ }^{1}$, PENCHOM PEUNGVICHA ${ }^{2}$, \\ KORNKANOK INGKANINAN $^{3}$, NETI WARANUCH ${ }^{3}$ and NARONG SARISUTA ${ }^{1}$ \\ Departments of ${ }^{1}$ Manufacturing Pharmacy, and ${ }^{2}$ Physiology, Faculty of Pharmacy, Mahidol University, \\ Bangkok 10400; ${ }^{3}$ Department of Pharmaceutical Technology, Faculty of Pharmaceutical Sciences, \\ Naresuan University, Phitsanulok 65000, Thailand
}

Received September 22, 2010; Accepted November 16, 2010

DOI: $10.3892 /$ etm.2010.172

\begin{abstract}
The present study examined the antioxidant activity and protective effect of extracts from Asparagus racemosus roots against Lipofectamine-induced apoptosis. Five fractions from a successive extraction process ranging from non-polar to more polar solvents were obtained. The total saponin content as a marker in terms of diosgenin equivalent value of the root extracts was found to be in the range of 240-420 $\mu \mathrm{g} /$ mg extract, with higher values for the ethanol and aqueous fractions. The antioxidant activity measured using the DPPH method in terms of mean effective concentration $\left(\mathrm{EC}_{50}\right)$ of the aqueous fraction was found to be $600 \mu \mathrm{g} / \mathrm{ml}$ as compared to $1.5 \mu \mathrm{g} / \mathrm{ml}$ of ascorbic acid. It is proposed that Asparagus racemosus root extracts effectively inhibit Lipofectamineinduced apoptosis by their protective effect, and may serve as an advantageous alternative option for gene delivery.
\end{abstract}

\section{Introduction}

In India, the plant Asparagus racemosus Willd. (Liliaceae) is commonly called Satavari, Satawar or Satmuli in Hindi, Satavari in Sanskrit and Shatamuli in Bengali. In Thailand, it is called Sam-Sib or Sam-Roi-Rak. The plant is a spinous undershrub with tuberous short rootstock bearing numerous succulent tuberous roots (30-100 cm long and $1-2 \mathrm{~cm}$ thick) that are silvery white or ash-colored externally and white internally (1). Its pharmacological applications, particularly from the root extracts, have recently been found to possess a phytoestrogenic effect, an effect on neurodegenerative disorders, as well as antidiarrhoeal, antidyspepsia, adaptogenic, cardioprotective,

Correspondence to: Professor Narong Sarisuta, Department of Manufacturing Pharmacy, Faculty of Pharmacy, Mahidol University, 447 Sri-Ayudhya Road, Bangkok 10400, Thailand

E-mail: pynst@mahidol.ac.th

Key words: Asparagus racemosus, antioxidant activity, apoptosis, Lipofectamine, human lung epithelial cells, root extracts antibacterial, immunoadjuvant and antitussive effects. The root extracts of Asparagus racemosus have been employed in two major forms as methanolic and aqueous extracts, the products of which include root extract in tablet form, root powder in tablet form and root extract in syrup form (1).

Among the many biological activities of Asparagus racemosus, it has been reported to have antioxidant activity. Methanolic root extracts were found to markedly increase superoxide dismutase, catalase and ascorbic acid, while decreasing lipid peroxidase product (malondialdehyde) in rats (2,3). In addition, Asparagus racemosus has recently been shown to contain ten steroidal saponins (4) and racemofuran (5). The aqueous extracts have also been shown to exhibit an antioxidant effect in rat liver mitochondria by protecting against the radiation-induced loss of protein thiols and inactivation of superoxide dismutase (6), and the amelioration of oxidative stress and hepatotoxicity (7).

Cationic liposomes are among the non-viral vectors considered to be promising tools for gene delivery through their formation of a lipoplex with nucleic acids, such as RNA or DNA $(8,9)$. Their advantages include biocompatibility, a plasmid-independent structure, the opportunity for chemical or physical manipulation, and large-scale production and cost-effectiveness, while drawbacks include low transfection efficiency (10) and cytotoxicity (11).

Toxicity studies of cationic liposomes revealed a significant effect when the positive charge density was increased. Lipofectamine (commercially available polyvalent cationic liposomes) was reported to possess a higher transfection efficiency than Lipofectin and DOTAP (monovalent cationic liposomes) in the macrophage RAW264.7 cell line $(12,13)$. Nonetheless, cationic lipids with a higher positive charge density are generally more toxic (14). Moreover, some reports on toxicity have found that cationic liposomes with a monovalent positive charge (stearylamine) induced apoptosis and the production of reactive oxygen species (ROS) (15) in the RAW264.7 (16) and mouse immature B (WEHI 231) cell lines (17). In in vivo toxicity studies of differently charged liposomes by intratracheal instillation in mice, Lipofectamine was found to cause much greater toxicity than DOTAP in a 
dose-dependent manner, which was associated with ROS generation, while neutral and negative liposomes were not toxic at the relevant concentration (18). Therefore, ROS are considered to play a key role in cationic liposome-mediated cytotoxicity. This effect was found to be charge-dependent and was prevented by ROS scavengers.

Toxicity and apoptosis induced by cationic liposomes as well as their mechanisms have been found to be definitely associated with ROS generation. Thus, the antioxidant effect of Asparagus racemosus root extract may be applicable for protecting cells from apoptosis related to ROS generation. Such an application would provide an alternative for scavenging ROS, and hence improve transfection efficiency. In this study, different fractions of Asparagus racemosus root extracts from successive extraction with different solvents were investigated in regards to their antioxidant activity and protective effect against Lipofectamine-induced apoptosis in human lung epithelial H460 cells.

\section{Materials and methods}

Chemicals and reagents. Lipofectamine was obtained from Invitrogen (Carlsbad, CA, USA). This liposomal formulation is composed of a 3:1 mixture of cationic lipid DOSPA and neutral lipid DOPE. Oleanolic acid, diosgenin, 2,2-diphenyl1-picrylhydrazyl (DPPH), and Hoechst ${ }^{\circledR} 33342$ dye were purchased from Sigma Chemical Co. (St. Louis, MO, USA). Thin layer chromatography silica gel plates $\left(60 \mathrm{~F}_{254}\right)$, ascorbic acid, hexane, ethanol, acetone, methanol, ethyl acetate, chloroform and dichloromethane were purchased from Merck KG (Darmstadt, Germany).

Plant materials. The roots of Asparagus racemosus were collected from Tak Province, Thailand. The plants were identified by the botanical staff, and the voucher specimen of the plant was deposited in the herbarium of the Faculty of Pharmaceutical Sciences, Naresuan University, Phitsanulok, Thailand.

Successive extraction of Asparagus racemosus roots. Asparagus racemosus roots were dried and minced into powder, and then successively extracted with solvents starting from non-polar (hexane) to more polar (water) solvents. The hexane fraction was filtered and evaporated by a rotary evaporator (Eyela ${ }^{\circledR}$ A-3S; Tokyo Rikakikai, Japan), after which soft yellow paste was obtained and named AR1-1. The marc was further extracted with $95 \%$ ethanol, filtrated and evaporated, after which the dark brown viscous liquid was obtained and named AR1-2. The residual marc was further extracted with water at $80^{\circ} \mathrm{C}$. After filtration, the aqueous fraction was divided into two portions, one of which was evaporated and freeze-dried until brown powder was obtained and named AR1-3. The other portion was added to acetone and the resulting precipitate was separated out from the solution. Both the solution and precipitate were evaporated, freeze-dried, and named AR1-4 and AR1-5, respectively.

Thin layer chromatography (TLC) fingerprint. TLC is one of several techniques useful for the identification of phytochemical compounds $(19,20)$. In this study, solutions of oleanolic acid and diosgenin $(0.5 \mathrm{mg} / \mathrm{ml})$ in methanol were used as known references for triterpene and steroid structure, respectively $(21,22)$. The samples of the Asparagus racemosus extracts were prepared by dissolving fractions of AR1-1, AR1-2 and AR1-3 to AR1-5 (10 mg/ml) in ethyl acetate, methanol and water, respectively. All samples were filtered through a $0.2-\mu \mathrm{m}$ nylon membrane filter, after which $8 \mu \mathrm{l}$ was spotted by Autospot equipped with a scanner and camera $\left(\mathrm{Camag}^{\circledR}\right.$; Limonat V, Switzerland) on TLC silica gel plates and air-dried for $5 \mathrm{~min}$. The plates with the oleanolic acid and AR1-1 samples were developed with system I (2:1, hexane:ethyl acetate) (19), while those of diosgenin and AR1-2 to AR1-5 samples were developed with system II (6.4:5:1, chloroform:methanol:water) (23). After completion, the plates were dried at $100-110^{\circ} \mathrm{C}$ for $5 \mathrm{~min}$, sprayed with $10 \mathrm{ml}$ anisaldehyde-sulfuric acid reagent, heated at $105^{\circ} \mathrm{C}$ for $5-10 \mathrm{~min}$ and visualized under white and UV light (366 nm) for TLC fingerprints. This experiment was performed in duplicate.

Total saponin quantification. The total saponin content of Asparagus racemosus extracts was determined as described by Makkar et al (21) and Xi et al (24). Sample solutions of diosgenin $(0.5 \mathrm{mg} / \mathrm{ml})$ in methanol and those of AR1-1, AR1-2 and AR1-3 to AR1-5 (4 mg/ml) in dichloromethane, methanol and water, respectively, were prepared and filtered through a $0.2-\mu \mathrm{m}$ nylon membrane filter before use. A $250-\mu 1$ portion of $8 \% \mathrm{w} / \mathrm{v}$ vanillin solution in absolute ethanol was added to $250 \mu \mathrm{l}$ of sample, which was subsequently mixed with $2.5 \mathrm{ml}$ $72 \% \mathrm{v} / \mathrm{v}$ sulfuric acid, incubated in a water bath at $60^{\circ} \mathrm{C}$ for $10 \mathrm{~min}$ and finally cooled in an ice bath for $5 \mathrm{~min}$. The absorbance of this mixture was measured at $544 \mathrm{~nm}$ (Perkin Elmer Lambda 35; Perkin Elmer, Waltham, MA, USA). The calibration curve of diosgenin at a high degree of linearity with a correlation coefficient $\left(\mathrm{r}^{2}\right)$ of 0.9991 was achieved across the specified range of 8.3-41.6 $\mu \mathrm{g} / \mathrm{ml}$. The diosgenin equivalent (DGE) $(\mu \mathrm{g} / \mathrm{mg}$ extract) was used as reference in determining the total amount of saponins in each fraction of the extracts. This experiment was performed in triplicate.

Antioxidant activity testing by DPPH assay. The DPPH assay for assessing the antioxidant activity of the Asparagus racemosus extracts was carried out as described by BrandWilliams et al (25), with minor modifications. The absorbance of the DPPH solution in methanol was measured at $515 \mathrm{~nm}$ (Perkin Elmer Lambda 35), and a calibration curve at a very high degree of linearity with a correlation coefficient $\left(\mathrm{r}^{2}\right)$ of 0.9999 was achieved across the specified range of 10-100 $\mu \mathrm{M}$. Solutions of AR1-1, AR1-2 and AR1-3 to AR1-5 (4 mg/ $\mathrm{ml})$ were prepared in dichloromethane, methanol and water, respectively, $200 \mu \mathrm{l}$ of which was mixed with $1,400 \mu \mathrm{l}$ of $60 \mu \mathrm{M}$ DPPH solution. The decrease in absorbance was determined at 0,1 and every $15 \mathrm{~min}$ until $60 \mathrm{~min}$. The percentage of DPPH remaining at $60 \mathrm{~min}$ was determined and plotted as a function of the AR1-4 concentration. L-ascorbic acid was used as a positive control. The antioxidant activity was expressed in terms of the mean effective concentration $\left(\mathrm{EC}_{50}\right)$, which was defined as the amount of antioxidant that could decrease the initial DPPH concentration by $50 \%$.

Cell culture. Human lung epithelial NCI-H460 cells were obtained from the American Type Culture Collection 
Table I. $R_{f}$ values and color zones of TLC fingerprints of oleanolic acid and AR1-1 (hexane fraction) developed with system I, and diosgenin, AR1-2 (ethanol fraction) and AR1-3 to AR1-5 (aqueous fractions) developed with system II, visualized under white and UV light $(366 \mathrm{~nm})$.

\begin{tabular}{|c|c|c|c|}
\hline Compound & $\mathrm{R}_{\mathrm{f}}$ & Color under white light & Color under UV light (366 nm) \\
\hline Oleanolic acid & 0.31 & Blue & Brown \\
\hline AR1-1 (hexane fraction) & $\begin{array}{l}0.38 \\
0.44 \\
0.56 \\
0.69 \\
0.81\end{array}$ & $\begin{array}{l}\text { Blue } \\
\text { Light blue } \\
\text { Light blue } \\
\text { Blue } \\
\text { Dark blue }\end{array}$ & $\begin{array}{l}\text { Violet } \\
\text { Light brown } \\
\text { Pink } \\
\text { Red } \\
\text { Red }\end{array}$ \\
\hline Diosgenin & 1.00 & Yellow-green & Brown \\
\hline AR1-2 (ethanol fraction) & $\begin{array}{l}0.24 \\
0.34 \\
0.45\end{array}$ & $\begin{array}{l}\text { Light green } \\
\text { Light green } \\
\text { Dark green }\end{array}$ & $\begin{array}{l}\text { Light brown } \\
\text { Light brown } \\
\text { Dark brown }\end{array}$ \\
\hline AR1-3 (aqueous fraction) & $\begin{array}{l}0.24 \\
0.34 \\
0.45\end{array}$ & $\begin{array}{l}\text { Light green } \\
\text { Light green } \\
\text { Green }\end{array}$ & $\begin{array}{l}\text { Light brown } \\
\text { Light brown } \\
\text { Brown }\end{array}$ \\
\hline AR1-4 (aqueous fraction) & $\begin{array}{l}0.24 \\
0.34 \\
0.45\end{array}$ & $\begin{array}{l}\text { Light green } \\
\text { Light green } \\
\text { Green }\end{array}$ & $\begin{array}{l}\text { Light brown } \\
\text { Light brown } \\
\text { Brown }\end{array}$ \\
\hline AR1-5 (aqueous fraction) & $\begin{array}{l}0.24 \\
0.34 \\
0.45\end{array}$ & $\begin{array}{l}\text { Light green } \\
\text { Light green } \\
\text { Green }\end{array}$ & $\begin{array}{l}\text { Light brown } \\
\text { Light brown } \\
\text { Brown }\end{array}$ \\
\hline
\end{tabular}

(Manassas, VA, USA). The cells were cultured in RPMI-1640 medium (Invitrogen) supplemented with $5 \%$ fetal bovine serum, $2 \mathrm{mM}$ L-glutamine, $100 \mathrm{U} / \mathrm{ml}$ of penicillin and $100 \mu \mathrm{g} /$ $\mathrm{ml}$ of streptomycin. The cells were grown in a humidified atmosphere of $5 \% \mathrm{CO}_{2}$ at $37^{\circ} \mathrm{C}$ until they reached over $80 \%$ confluence. The cells were subsequently passaged by the use of a solution containing $0.05 \%$ trypsin and $0.5 \mathrm{mM}$ EDTA.

Antiapoptotic effect in $H 460$ cells. The aqueous fraction AR1-4 (10 mg/ml) was dissolved in water and filtered through a $0.2-\mu \mathrm{m}$ nylon membrane filter before use. Cells $\left(3 \times 10^{4} /\right.$ well) were seeded in a 96-well plate in $100 \mu$ l of culture medium and grown for $24 \mathrm{~h}$. The subconfluent monolayer of cells was washed once with PBS and once with RPMI-1640. Subsequently, $100 \mu \mathrm{l}$ of RPMI-1640 was added, and the cells were untreated or pre-treated with various concentrations of AR1-4 $(100,500$ and $1,000 \mu \mathrm{g} / \mathrm{ml})$ for $1 \mathrm{~h}$, and then treated with Lipofectamine $(20 \mu \mathrm{g} / \mathrm{ml})$ for $6 \mathrm{~h}$. The untreated cells were used as a control. Apoptosis was determined by the Hoechst 33342 assay.

For Hoechst 33342 staining, cells were incubated with $10 \mu \mathrm{g} / \mathrm{ml}$ of Hoechst 33342 dye at $37^{\circ} \mathrm{C}$ for $30 \mathrm{~min}$. Analysis for apoptosis was carried out by scoring the percentage of cells having intensely condensed chromatin and/or fragmented nuclei by fluorescence microscopy (Axiovert 25 CFI; Carl Zeiss, USA). Approximately 1,000 nuclei from random fields were analyzed for each sample. The percentage of apoptosis was calculated as (apoptotic nuclei/total nuclei) x 100\%. The experiment was performed in triplicate.

\section{Results and Discussion}

Standardization of Asparagus racemosus extracts. Asparagus racemosus extracts contain saponins as the main constituents (26). The major constituents of Asparagus racemosus in methanolic extract are steroidal saponins, which have been separated, purified and termed 'Shatavarin'. Ten derivatives of Shatavarin have been defined as Shatavarin I to X $(1,4)$. Gautam et al (23) found that an Asparagus racemosus aqueous decoction contained steroidal saponin, alkaloids, proteins, starch, tannin and mucilage. Agrawal et al (7) carried out screening tests and reported positive results for steroids, phytosterols, carbohydrates, tannins, anthraquinones, saponins, glycosides and flavonoids, and negative results for terpenoids, amino acids and alkaloids. Most recently, Visavadiya and Narasimhacharya (26) found that most of the phytoconstituents in Asparagus racemosus root are saponins $(8.83 \%)$, while the remaining constituents are polyphenols $(1.69 \%)$, phytosterols $(0.79 \%)$, ascorbic acid $(0.76 \%)$ and flavonoids $(0.48 \%)$.

Since saponins are found in both aqueous and methanolic extracts of Asparagus racemosus and can be purified successfully to pure compounds, they were considered as markers in this study. Standardization of Asparagus racemosus in this study involved the confirmation of the presence of saponins and control of the quality of Asparagus racemosus extracts by examining the TLC fingerprints and total saponin content.

Thin layer chromatographic fingerprints. The anisaldehydesulfuric acid reagent is generally used to detect phenol, sugar, 


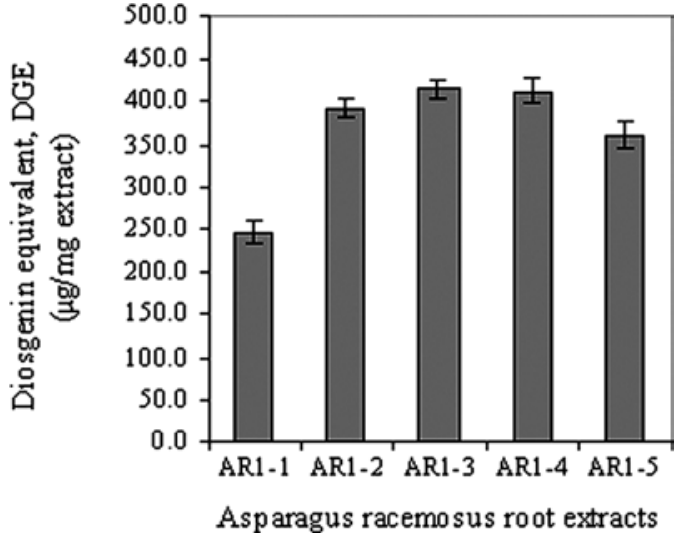

Figure 1. Total saponin content of AR1-1 (hexane fraction), AR1-2 (ethanol fraction) and AR1-3 to AR1-5 (aqueous fractions) of Asparagus racemosus root extracts in terms of the diosgenin equivalent (DGE) $(\mu \mathrm{g} / \mathrm{mg}$ extract). Plots are the mean $\pm \mathrm{SD}(\mathrm{n}=3)$.

steroid and terpene, which will turn violet, blue, red, grey or green, respectively. It was found that the TLC fingerprints of oleanolic acid and AR1-1 developed with system I exhibited a blue color, while those of diosgenin and AR1-2 to AR1-5 developed with system II exhibited yellow-green and green colors under white light. Detailed information regarding the $R_{f}$ values and color zones is listed in Table $I$, and indicates that the compounds detected in AR1-1 to AR1-5 using this reagent may contain the structure of phenol, sugar, steroid and/ or terpene in their molecules. Oleanolic acid, as triterpene, showed only a blue stripe, whereas AR1-1 exhibited many stripes with a blue color, one being on top of the lane. This indicates that AR1-1 may contain some saponins, including triterpenoid saponin. The more polar developing system II was applied to diosgenin and to fractions AR1-2 to AR1-5, which appeared to contain some steroidal saponins since green stripes similar to that of diosgenin appeared.

Among all of the fractions of the Asparagus racemosus extracts, the compounds of AR1-1 differed from those of AR1-2 to AR1-5. Fractions AR1-2 to AR-5 consisted of similar constituents as evidenced by the same pattern of TLC fingerprints with three main bands and a zone near the starting spot. Moreover, the band at an $\mathrm{R}_{\mathrm{f}}$ value of 0.45 was prominent in AR1-2, while a zone near the starting spot was more pronounced in fractions AR1-3 to AR1-5. As a result, solubility of the former was increased using $95 \%$ ethanol as an extracting solvent, whereas solubility of the latter was increased using water as an extracting solvent. This was determined by the successive extraction using non-polar to more polar solvents.

Total saponin quantification. Vanillin-sulfuric acid reagent was used for derivatization of the saponins having an $\mathrm{OH}$ group at their $\mathrm{C}-3$ position to give chromogens. The chromogens formed were not dependent on the nature of the sugar moieties (21). Among all of the Asparagus racemosus extracts, the amount of DGE could be ranked in order as: AR1-2 AR1-3 AR1-4 > AR1-5 > AR1-1, as shown in Fig. 1. It is apparent that the highest amount of saponins was found in the 95\% ethanol and aqueous fractions, but with a difference in the type of saponins.
A

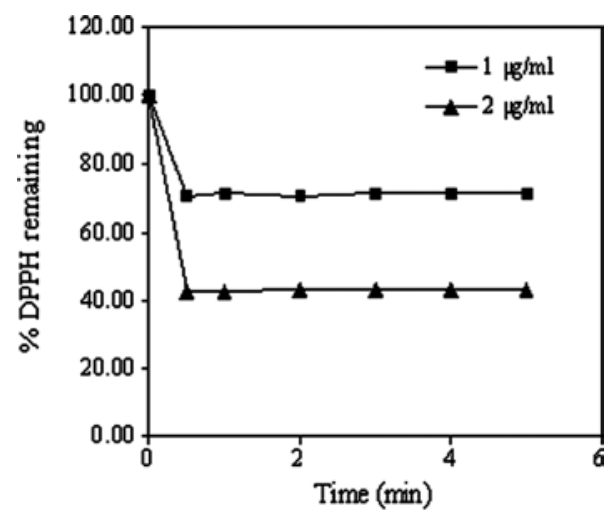

B

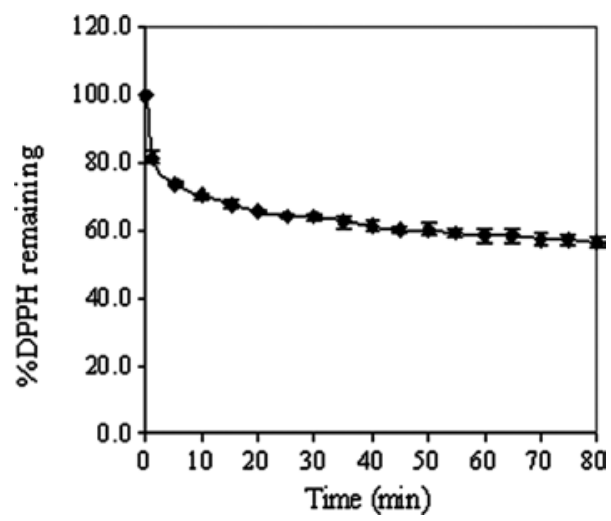

Figure 2. Reaction kinetics of the antioxidant activity of (A) ascorbic acid $(1$ and $2 \mu \mathrm{g} / \mathrm{ml})$ and (B) AR1-4 $(0.5 \mathrm{mg} / \mathrm{ml})$ with DPPH. Plots are the mean $\pm \mathrm{SD}(\mathrm{n}=3)$

Antioxidant activity testing by DPPH assay. In this study, ascorbic acid was used as a positive control, and AR1-4 was chosen as a representative based on its highest saponin content. Firstly, the reaction kinetics in the antioxidant activity of both ascorbic acid and AR1-4 with DPPH were carried out to determine the suitable incubation time before measurement. These were found to reach a steady state by 1 and $60 \mathrm{~min}$, respectively (Fig. 2). The time to reach steady state, as classified by Brand-William et al (25), for reaction kinetics of ascorbic acid was found to be much more rapid $(<1 \mathrm{~min})$ than that of AR1-4 (60 min). Active compounds having antioxidant activity in AR1-4 would consist of a large complex molecule with slow reaction kinetics, while small molecule of ascorbic acid could easily be subject to interaction with DPPH.

The mean effective concentrations $\left(\mathrm{EC}_{50}\right)$ of ascorbic acid and AR1-4, as shown in Fig. 3, were found to be 1.5 and $600 \mu \mathrm{g} / \mathrm{ml}$, respectively. Recently, Potduang et al (27) showed that the $\mathrm{EC}_{50}$ of a crude ethanol extract of Asparagus racemosus dry powdered root was $381.91 \mu \mathrm{g} / \mathrm{ml}$, which was relatively lower than that of the aqueous fraction AR1-4 from successive extraction in this study. The antioxidant activities in terms of the \% DPPH remaining of the various fractions of Asparagus racemosus extracts at a fixed concentration of $500 \mu \mathrm{g} / \mathrm{ml}$ are compared in Fig. 4; AR1-2 (95\% ethanol fraction) significantly exhibited the highest antioxidant activity compared to the other fractions. These results were consistent with those reported above. In addition, the antioxidant activities of fractions other than AR1-2 were almost in the same order of magnitude. 
$\mathbf{A}$

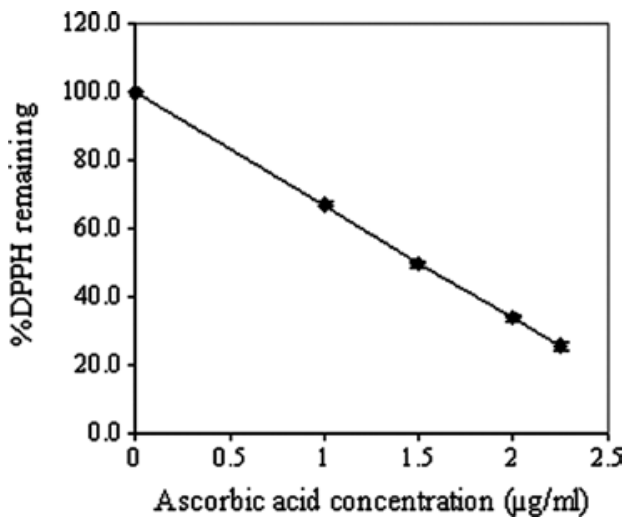

B

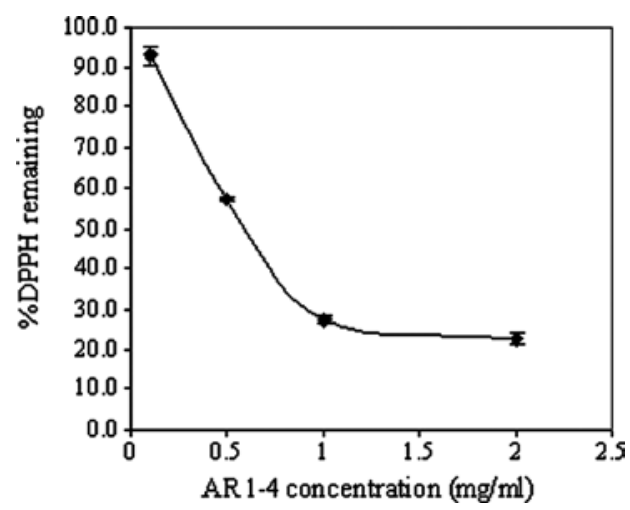

Figure 3. Mean effective concentrations $\left(\mathrm{EC}_{50}\right)$ of $(\mathrm{A})$ ascorbic acid and (B) AR1-4. Plots are the mean $\pm \mathrm{SD}(\mathrm{n}=3)$.

Although Asparagus racemosus extracts exhibit far less antioxidant activity than ascorbic acid when tested in vitro with the DPPH method, numerous studies have reported their substantial antioxidant effect when tested in vivo $(2,3,6,26)$. According to these studies, antioxidant enzymes (superoxide dismutase, catalase) and ascorbic acid were increased by the effects of Asparagus racemosus aqueous and methanolic extracts, although the underlying mechanism has not yet been elucidated. To date, there are no reports indicating that saponins of Asparagus racemosus extracts are the active compound responsible for this antioxidant effect.

Antiapoptotic effect in 4460 cells. The AR1-4 aqueous fraction was selected for the preliminary test to assess the antioxidant effect in cells, since its main constituents shown in the TLC fingerprint were similar to those of fractions AR1-3 and AR1-5 in terms of both main bands and intensity. Additionally, AR1-4 was more readily dissolved in water compared to the other fractions, which was more appropriate for the treatment of cells due to the non-toxicity of the water solvent. The results of the Hoechst assay showed that treatment of the H460 cells with Lipofectamine $(20 \mu \mathrm{g} / \mathrm{ml})$ caused extensive apoptosis compared to the control (Fig. 5). Upon pre-treatment of the cells with AR1-4, Lipofectamine-induced apoptosis was significantly decreased with an increasing concentration of AR1-4.

Toxicity and apoptosis induced by cationic liposomes as well as their mechanisms have been found to be clearly associated with ROS generation, which could effectively be inhibited by ROS scavengers or antioxidant enzymes, particularly superoxide dismutase $(11,16,28)$. The protective effect of AR1-4 against

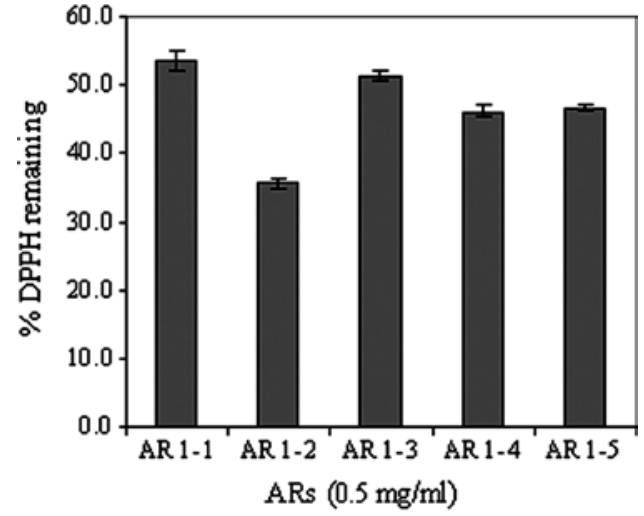

Figure 4. Percentage of remaining DPPH for AR1-1 (hexane fraction), AR1-2 (ethanol fraction) and AR1-3 to AR1-5 (aqueous fractions) of Asparagus racemosus extracts tested at the same concentration $(500 \mu \mathrm{g} / \mathrm{ml})$. Plots are the mean $\pm \mathrm{SD}(\mathrm{n}=3)$

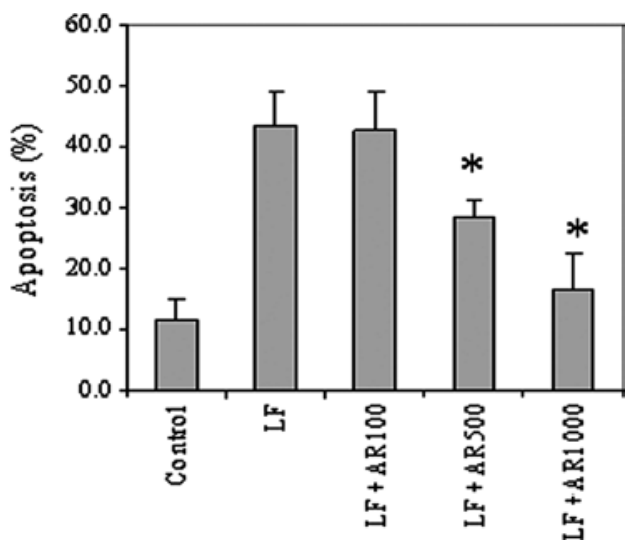

Figure 5. Apoptosis of untreated (control) H460 cells or H460 cells pretreated with AR1-4 at $100(\mathrm{LF}+\mathrm{AR} 100), 500$ (LF + AR500) and 1,000 (LF + AR1000) $\mu \mathrm{g} / \mathrm{ml}$ for $1 \mathrm{~h}$, after which they were treated with Lipofectamine $(20 \mu \mathrm{g} / \mathrm{ml})$ for $6 \mathrm{~h}$ and analyzed by Hoechst assay. Plots are the mean $\pm \mathrm{SD}$ $(n=3) .{ }^{*} p<0.05$ vs. Lipofectamine-treated control (LF).

Lipofectamine-induced apoptosis in this study can probably be attributed to the reduction in oxidative stress-induced toxicity imposed by its antioxidant activity. However, it is interesting to note that the antioxidant activity of AR1-4 with DPPH in this study was 400 times less than that of ascorbic acid, while it effectively protected the cells from apoptosis as compared to the untreated cells (Fig. 5). The results suggest that this antiapoptotic effect may be caused by the indirect enhancement of antioxidant enzymes, such as superoxide dismutase or catalase, rather than a direct antioxidant effect against ROS in the cells. This is supported by several studies showing that root extracts of Asparagus racemosus are capable of markedly increasing and protecting the inactivation of superoxide dismutase and catalase in rats $(2,3,6,7)$.

In conclusion, Asparagus racemosus extracts appear to be composed of saponins, the contents of which are richer in extracts from polar compared to non-polar solvents. Successive extraction resulted in fractions having different antioxidant activities. In addition, aqueous fraction AR1-4 was shown to exhibit a significant protective effect against Lipofectamineinduced apoptosis in human lung epithelial $\mathrm{H} 460$ cells. 


\section{Acknowledgements}

Financial support provided by the Thai Herbal NanoCosmeceuticals Coordinated Research Program, the National Nanotechnology Center, and the National Science and Technology Development Agency, Thailand, is gratefully acknowledged.

\section{References}

1. Bopana $\mathrm{N}$ and Saxena $\mathrm{S}$ : Asparagus racemosus ethnopharmacological evaluation and conservation needs. J Ethnopharmacol 110: 1-15, 2007.

2. Bhatnagar M, Sisodia SS and Bhatnagar R: Antiulcer and antioxidant activity of Asparagus racemosus Willd and Withania somnifera Dunal in rats. Ann NY Acad Sci 1056: 261-278, 2005.

3. Sairam K, Priyambada S, Aryya NC and Goel RK: Gastroduodenal ulcer protective activity of Asparagus racemosus an experimental, biochemical and histological study. J Ethnopharmacol 86: 1-10, 2003.

4. Hayes PY, Jahidin AH, Lehmann R, Penman K, Kitching W and Voss JJD: Steroidal saponins from the roots of Asparagus racemosus. Phytochemistry 69: 796-804, 2008.

5. Wiboonpun N,Phuwapraisirisan P and Tip-pyang S: Identification of antioxidant compound from Asparagus racemosus. Phytother Res 18: 771-773, 2004.

6. Kamat JP, Boloor KK, Devasagayam TPA and Venkatachalam SR: Antioxidant properties of Asparagus racemosus against damage induced by $\gamma$-radiation in rat liver mitochondria. J Ethnopharmacol 71: 425-435, 2000.

7. Agrawal A, Sharma M, Rai SK, Singh B, Tiwari M and Chandra R: The effect of the aqueous extract of the roots of Asparagus racemosus on hepatocarcinogenesis initiated by diethylnitrosamine. Phytother Res 22: 1175-1182, 2008.

8. Gao X, Kim KS and Liu D: Nonviral gene delivery: what we know and what is next. AAPS J 9: E92-E104, 2007.

9. Niidome T and Huang L: Gene therapy progress and prospects: nonviral vectors. Gene Ther 9: 1647-1652, 2002.

10. Strom $\mathrm{G}$ and Crommelin DJA: Liposomes: quo vadis? PSTT 1 19-31, 1998.

11. Dokka S, Toledo D, Shi X, Castronova V and Rojanasakul Y: Oxygen radical-mediated pulmonary toxicity induced by some cationic liposomes. Pharm Res 17: 521-525, 2000.

12. Dokka S, Toledo D, Shi X, Ye J and Rojanasakul Y: Highefficiency gene transfection of macrophages by lipoplexes. Int $\mathrm{J}$ Pharm 2006: 97-104, 2000.

13. Wolf BB and Green DR: Suicidal tendencies: apoptotic cell death by caspase family proteinases. J Biol Chem 274: 20049-20052, 1999.
14. Lv H, Zhang S, Wang B, Cui S and Yan J: Toxicity of cationic lipids and cationic polymers in gene delivery. J Control Release 114: 100-109, 2006.

15. Almofti MR, Harashima H, Shinohara Y, Almofti A, Baba Y and Kiwada H: Cationic liposome-mediated gene delivery: biophysical study and mechanism of internalization. Arch Biochem Biophys 410: 246-253, 2003.

16. Aramaki Y, Takano S and Tsuchiya S: Induction of apoptosis in macrophages by cationic liposomes. FEBS Lett 460: 472-476, 1999.

17. Aramaki Y, Takano S, Arima H and Tsuchiya S: Induction of apoptosis in WEHI 231 cells by cationic liposomes. Pharm Res 17: 515-520, 2000

18. Dokka S, Toledo D, Shi X, Ye J and Rojanasakul Y: Highefficiency gene transfection of macrophages by lipoplexes. Int J Pharm 206: 97-104, 2000.

19. Uematsu Y, Hirata K, Suzuki K, Iida K and Kamata K: Investigation of spectrophotometrically determined substances in Yucca extracts by GC/MS, TLC and on-column injection GC. J Food Hyg Soc Japan 45: 141-145, 2004.

20. Zhao L, Huang C, Shan Z, Xiang B and Mei L: Fingerprint analysis of Psoralea corylifolia L. by HPLC and LC-MS. J Chromatogr B Analyt Technol Biomed Life Sci B821: 67-74, 2005.

21. Makkar HPS, Siddhuraju P and Becker K (eds): Plant Secondary Metabolites. Serries Methods in Molecular Biology. Vol. 393. Humana Press, New Jersey, 2007.

22. Wojciak-Kosior M: Application of high performance thin-layer chromatography to separation of oleanolic acid, ursolic and belulinic acids. J Pre-Clin Clin Res 1: 176-178, 2007.

23. Gautam M, Diwanay S, Gairola S, Shinde Y, Patki P and Patwardhan B: Immunoadjuvant potential of Asparagus racemosus aqueous extract in experimental system. J Ethnopharmacol 91: 251-255, 2004.

24. Xi M, Hai C, Tang H, Chen M, Fang K and Liang X: Antioxidant and antiglycation properties of total saponins extracted from traditional Chinese medicine used to treat diabetes mellitus. Phytother Res 22: 228-237, 2008.

25. Brand-Williams W, Cuvelier ME and Berset C: Use of a free radical method to evaluate antioxidant activity. Lebensm-Wiss U-Technol 28: 25-30, 1995.

26. Visavadiya NP and Narasimhacharya AVRL: Asparagus root regulates cholesterol metabolism and improves antioxidant status in hypercholesteremic rats. Evid Based Complement Altern Med 6: 219-226, 2009.

27. Potduang B, Meeploy M, Giwanon R, Benmart Y, Kaewduang M and Supatanakul W: Biological activities of Asparagus racemosus. Afr J Tradit Complement Altern Med 5: 230-237, 2008.

28. Kongkaneramit L, Sarisuta N, Azad N, Lu Y, Iyer AK V, Wang L and Rojanasakul Y: Dependence of reactive oxygen species and FLICE inhibitory protein on Lipofectamine-induced apoptosis in human lung epithelial cells. J Pharmacol Exp Ther 325: 969-977, 2008. 